\title{
Video Conferencing in the Intravitreal Injection Clinic in Response to the COVID-19 Pandemic
}

\author{
Habiba Saedon • Gemma Gould • Minara Begum • Tariq M. Aslam
}

Received: May 1, 2020 / Published online: May 25, 2020

(C) The Author(s) 2020

\section{ABSTRACT}

Purpose: To share a useful intervention to minimize risk of COVID-19 infection to both healthcare workers and patients in the eye clinic. Methods: We present our experience of virtual, within-clinic remote visual acuity assessment to reduce the risk of infection with COVID-19.

Results: Along with standard recommendations for personal protective equipment and hand hygiene to contain viral spread and treating only urgent cases, remote within-clinic visual acuity testing and consultations can be undertaken with minimal specialist equipment and appears to provide useful information whilst being acceptable to patients.

Conclusion: Ophthalmology practice must adapt in order to combat COVID-19. This measure can easily be incorporated into daily practice to reduce both patient footfall within the department and close contact between patient and healthcare practitioners.

Digital features To view digital features for this article go to https://doi.org/10.6084/m9.figshare.12302480.

H. Saedon $(\bowtie) \cdot$ G. Gould · M. Begum · T. M. Aslam Manchester Royal Eye Hospital, Manchester, UK e-mail: Habiba.Saedon@mft.nhs.uk

T. M. Aslam

Division of Pharmacy and Optometry, Faculty of Biology, Medicine and Health, School of Health Sciences, The University of Manchester,

Manchester, UK
Keywords: COVID-19; Tele-ophthalmology; Visual acuity

\section{Key Summary Points}

The emergence of the novel coronavirus SARS-CoV-2, and the resulting disease COVID-19, in December 2019 has created a major international public health challenge.

Ophthalmologists have been identified as being at significant risk of becoming infected with coronavirus because of the close proximity to patients.

Remote within-clinic visual acuity testing and consultations can be undertaken with minimal specialist equipment to reduce risk of viral spread and appears to provide useful information whilst being acceptable to patients.

Ophthalmology practice must adapt in order to combat COVID-19.

\section{INTRODUCTION}

The emergence of the novel coronavirus SARSCoV-2, and the resulting disease COVID-19, in 
December 2019 has created a major international public health challenge. Ophthalmologists have been identified as being at significant risk of becoming infected with coronavirus because of the close proximity to patients and transmission via mucous membranes $[1,2]$. It is therefore imperative to protect staff with appropriate personal protective equipment (PPE) and prevent spread from patients. Exposure time and risk of cross infections need to be minimised by assessing and changing patterns of workflow [3]. One of the most severely affected areas outside China was Italy, where two centres described changes made to reduce patient flow by postponing deferrable activities and adopting telephone screening [4].

As the pandemic stabilises, focus now turns to the reintroduction of non-acute services, reinstating and continuation of care for patients with ongoing sight-threatening disease, many of whom did not attend appointments for fear of contracting COVID-19.

Several measures have been taken to minimise patient and staff risk of virus spread, whilst balancing the need to continue to see patients in order to prevent sight loss. These include use of PPE, only treating urgent conditions and maintaining social distancing as far as is possible during the clinic visit. International documents provide detailed guidance on managing patients during this pandemic [5]. In the UK, the Royal College of Ophthalmologists has issued guidance to limit investigations unless absolutely required, including possible exclusion of vision testing for patients regularly attending injection clinics for wet age-related macular degeneration [6].

The intravitreal injection service at Manchester Royal Eye Hospital is served by one main and three satellite Macular Treatment Centres spread throughout the city. This reduces the risk of spreading the virus by way of smaller numbers attending each clinic and faster throughput of patients in their clinic journey. However, upon entering the clinical area, measures can be taken to further reduce the risk and minimise contact but still provide high-quality care. Once such method is by performing visual acuity testing using a remote electronic platform.
Visual acuity measurement is one of the most important steps in the ophthalmic examination. It is typically performed in a small enclosed room, standing close to the patient for a period of time and handing occluder equipment to-and-fro. Recent recommendations have therefore suggested that it should be omitted whenever possible to reduce transmission risk. However, relying on subjective changes in vision reported by the patient alone could lead to additional investigation and inappropriate treatment. By incorporating this new technique of visual acuity measurement using a real-time virtual platform, objective changes in visual acuity can be identified with reduced risk of disease transmission and patients managed more appropriately.

\section{METHODS}

Patients are informed in advance by letter that changes will be made to the usual process during their visit. The patient is booked into the clinic by the receptionist and at this point screening questions are asked to elicit any symptoms of or contact with coronavirus. The patient is directed to a visual acuity testing room, maintaining the recommended distance between individuals and invited to take a seat.

From this point, the clinician communicates with the patient via video link between a computer in the patient's room and in the assessor's room using standard webcams and video conferencing software. In the patient's room, the screen is placed close to the patient's seat so they can clearly see the doctor. Equally, the doctor can clearly see the patient's face and upper body. The consultation and acuity test are conducted in a real-time virtual manner (Fig. 1). The patient is instructed in the use of the occluder and pinhole, if required, which is placed conveniently in front of them within easy reach. The patient is asked to read the visual acuity chart directly ahead of them. The clinician can see if the occluder is being used correctly through the video link and has an electronic image of the current chart on his phone to allow them to assess the patient's performance and direct them accordingly. 


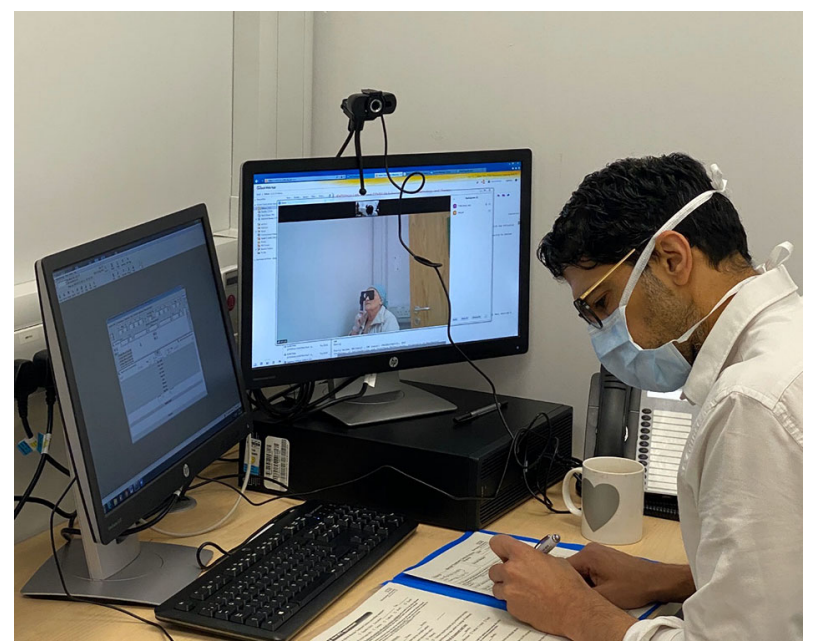

Fig. 1 Real-time virtual consultation showing a doctor testing a patient's visual acuity

Visual acuity is measured in the standard manner under photopic conditions at $4 \mathrm{~m}$ of distance with the logMAR chart.

A discussion can then take place between the patient and assessor regarding subjective changes in vision or other pertinent history without the constraint of needing to reduce the length of the consultation to minimise contact time. The management plan may also be discussed in detail without needing to shorten the length to reduce exposure. Following consultation, the patient may progress directly to the injection room for treatment. After the patient has left the room, the seating area, including occluder and computer screen, is appropriately disinfected ready for the next patient.

Ethics committee approval was not required for this article. Informed consent was obtained by all participants.

\section{RESULTS}

So far in our practice, 10 patients have had consultation take place in this manner. They were attending for booked treatment of age-related macular degeneration or emergency attendance if they felt their vision had deteriorated since appointments had been cut back for other conditions such as diabetic macular oedema. The consultations have been done by one of two doctors or an optometrist. Clinical staff have reported that they are able to establish rapport easily without need for their mask and could take their time to discuss and allay fears. All patients were able to understand the requirements of them, having being very used to regular vision checks and they appeared to adapt well to the new technique. In the current climate, many of the patients tested may otherwise have not had formal visual acuity assessment and clinicians reported benefits of the extra information gleaned in terms of reassurance to patient and impact on decisions for retreatment period. In one emergency case, full and lengthy discussion with a patient and accurate vision test prevented the need for full slit lamp exam and further appointment. Feedback received from patients suggests that it is an acceptable means of communication with them. They feel reassured that social distancing is maintained, are more likely to attend their appointment and therefore maintain their vision.

\section{DISCUSSION}

One example benefit of this method is that it allows safer extension of treatment to a level which is unlikely to be detrimental if there is documented evidence that visual acuity is stable. Because of the distance between the 
patient and doctor, the wearing of a face mask may be optional. If not worn, it allows patients to see the whole of the doctor's face. As the demographic of patients treated have a higher prevalence of hearing issues, this can aid significantly in the communication between the patient and doctor. As the visual acuity testing and consultation take place in the same room, the patient does not need to move between different rooms, saving both time and exposure to different rooms.

Current practice involves deferring all the elective activity and providing clinical visits only for acute and chronic sight or life-threatening conditions [7]. Furthermore, clinical and surgical activity should be reorganized into different levels of dedicated precautions based on risk assessment and severity of the condition.

Even prior to the current COVID-19 pandemic, virtual clinics have been increasingly used in medical retina clinics. In these clinics, the patient has imaging performed, but no faceto-face consultation takes place and images are analysed at a later date [8-10]. This has been shown to significantly reduce the visit time for patients attending these clinic appointments and also has the advantage of allowing a higher number of patients to be seen, thereby maximising efficiency.

One study based in rural India showed that visual acuity measurements using a remotely controlled computerized VA chart was comparable to the conventional face-to-face method in a hospital-based population. In this study, digital VA testing systems along with communication in the patient's native dialect was effectively integrated into the tele-eyecare model [11].

Home self-testing of vision has been extensively explored and many systems exist for this, but definitive clinical validation for such testing is often lacking [12]. Problems can arise, for example, from access to and difficulties in setting up and using technologies, lack of psychophysical consistency of different device screens, maintaining correct distance and algorithm accuracy [13]. In practice, most patients arrive at their hospital appointments without a home measure of their current acuity and the system we describe allows a means of measuring this without significant risk of exposure to infection.

Limitations to our system include the need to connect two computers using an electronic platform, necessitating internet access and computer equipment as well as a small amount of preparation time to set up the link. Additional peripheral equipment such as webcams may be required depending on existing facilities, although mobile telephones may be an alternative. In our experience, use of the occluder and direction through the acuity test were straightforward for patients who were all regular attenders and used to visual acuity assessment. However, the system was tested only in a macular treatment unit where patients are accustomed to regular visits with repeated vision tests and it may not translate easily to other clinics or to new patients.

Further formal studies with larger numbers and comparison to gold standard vision testing would be needed to prove the validity and reliability of testing. However, our albeit limited experience of the system has demonstrated it to be a useful technique, especially when vision might not otherwise be tested, to obtain a visual acuity measure with consultation whilst limiting COVID-19 exposure.

\section{CONCLUSION}

In the current climate, changes are required in order to control viral spread and try to maximize patient and healthcare workers' safety. This article demonstrates one method to reduce patient contact and maintain social distancing. In combination with other techniques, it may help to reduce exposure for both clinician and patient to transmission whilst still allowing for useful information of history and visual acuity to be determined.

\section{ACKNOWLEDGEMENTS}

Funding. No funding or sponsorship was received for this overview nor for the publication of this article. 
Authorship. All named authors meet the International Committee of Medical Journal Editors (ICMJE) criteria for authorship for this article, take responsibility for the integrity of the work as a whole, and have given their approval for this version to be published.

Disclosures. Tariq M Aslam declares research grants, expert committees and advisory boards and lectures for Allergan, Novartis, Bayer, Bausch and Lomb, Oraya, Thea pharmaceuticals. None relevant to this article. Tariq $M$ Aslam is also the Editor in Chief for this journal. Habiba Saedon declares consultancy and research for Novartis and Bayer. Gemma Gould and Minara Begum have nothing to disclose.

Compliance with Ethics Guidelines. Ethics committee approval was not required for this article. Informed consent was obtained by all participants.

Data Availability. Data sharing is not applicable to this article as no datasets were generated or analysed during the current study.

Open Access. This article is licensed under a Creative Commons Attribution-NonCommercial 4.0 International License, which permits any non-commercial use, sharing, adaptation, distribution and reproduction in any medium or format, as long as you give appropriate credit to the original author(s) and the source, provide a link to the Creative Commons licence, and indicate if changes were made. The images or other third party material in this article are included in the article's Creative Commons licence, unless indicated otherwise in a credit line to the material. If material is not included in the article's Creative Commons licence and your intended use is not permitted by statutory regulation or exceeds the permitted use, you will need to obtain permission directly from the copyright holder. To view a copy of this licence, visit http://creativecommons.org/licenses/by$\mathrm{nc} / 4.0 /$.

\section{REFERENCES}

1. Jørstad ØK, Moe MC, Eriksen K, Petrovski G, Bragadóttir R. Coronavirus disease 2019 (COVID-19) outbreak at the Department of Ophthalmology, Oslo University Hospital. Norway Acta Ophthalmol. 2020;2019:2019-20.

2. Lu CW, Liu XF, Jia ZF. 2019-nCoV transmission through the ocular surface must not be ignored. Lancet. 2020;395(10224):e39. https://doi.org/10. 1016/s0140-6736(20)30313-5.

3. Wan KH, Huang SS, Young A, Chiu Lam DS. Precautionary measures needed for ophthalmologists during pandemic of the coronavirus disease 2019 (COVID-19). Acta Ophthalmol. 2020. https://doi. org/10.1111/aos.14438.

4. Parravano M, Borrelli E, Costanzo E, Sacconi R, Varano M, Querques G. Protect healthcare workers and patients from COVID-19: the experience of two tertiary ophthalmology care referral centers in Italy. Ophthalmol Ther. 2020. https:// doi.org/10.1007/s40123-020-00251-z.

5. Gharebaghi R, Desuatels J, Moshirfar M, Parvizi M, Daryabari SH, Heidary F. Preliminary clinical guidelines for ophthalmology practices. Med Hypothesis Discov Innov Ophthalmol. 2020;9(2): 149-58.

6. The Royal College of Ophthalmologists. RCOphth: management of ophthalmology services during the Covid pandemic. https://www.rcophth.ac.uk/wpcontent/uploads/2020/03/RCOphth-Managementof-Ophthalmology-Services-during-the-Covidpandemic-280320.pdf.

7. Romano MR, Montericcio A, Montalbano C, et al. Facing COVID-19 in ophthalmology department. Curr Eye Res. 2020;23:1-6.

8. Tsaousis KT, Empeslidis T, Konidaris VE, Kapoor B, Deane J. The concept of virtual clinics in monitoring patients with age-related macular degeneration. Acta Ophthalmol. 2016 Aug;94(5):e353-e355355.

9. Kortuem K, Fasler K, Charnley A, et al. Implementation of medical retina virtual clinics in a tertiary eye care referral centre. Br J Ophthalmol. 2018 Oct;102(10):1391-5.

10. Kern C, Kortuem K, Hamilton R, et al. Clinical outcomes of a hospital-based teleophthalmology service: what happens to patients in a virtual clinic? Ophthalmol Retina. 2019 May;3(5):422-8.

11. Sreelatha OK, Ramesh SV, Jose J, Devassy M, Srinivasan K. Virtually controlled computerised visual 
acuity screening in a multilingual Indian population. Rural Remote Health. 2014;14(3):2908.

12. Yeung WK, Dawes P, Pye A, et al. eHealth tools for the self-testing of visual acuity: a scoping review. NPJ Digit Med. 2019 Aug;22(2):82.
13. Ali ZC, Shakir S, Aslam TM. Perceptions and use of technology in older people with ophthalmic conditions. F1000Res. 2019;8:86. 